\title{
Driver Offender Courses in Selected European Countries
}

\section{Matus Sucha ${ }^{a}$, Margit Herle $^{b}$, Fatima Pereira da Silva ${ }^{c}$}

${ }^{a}$ Department of Psychology, Philosophical Faculty, Palacky University, Krizkovskeho 10, 77180 Olomouc, Czech Republic, e-mail:matus.sucha@upol.cz; corresponding author

${ }^{b}$ Schuhfried GmbH, Hyrtlstraße 45, 2340 Mödling, Austria, e-mail: herle@schuhfried.at

'Higher School of Education - Polytechnic Institute of Coimbra, Rua Dom João III, Solum, 3030-329 Coimbra, Portugal;

e-mail:mpereira@esec.pt

ABSTRACT: This paper summarizes the current situation in eleven European countries in the field of driver offender courses. As a background, driver behaviour models are presented, followed by the description of behaviour, performance, and personality factors as contributory factors to crashes, risky driver behaviour, and groups of risky drivers. Selected enforcement and rehabilitation models are listed. Data was collected using a questionnaire, which was elaborated on the basis of the opinions of experts discussed at international expert workshops. The study covered a total sample of eleven participants - TPI members representing each country. The data was analyzed systematically using a modified version of the Editing Analysis Style and thematic analysis as a tool for pattern recognition across qualitative data. The results are presented according to different countries and their specifics, followed by a summary of common approaches and groups of countries with the same approaches. The most common driver improvement courses are those for deviant drivers (dealing with drivers' bad habits) and for drivers who drove under the influence of alcohol and drugs. Driver improvement courses are obligatory in six out of the eleven countries, while in three countries they are optional. We conclude that it must be ensured that there are no negative side effects and that the courses lead to benefits for the public. Therefore, all driver improvement courses must be driven by theory and evidence and designed to avoid overconfidence and increased risk exposure - risky behaviour should be normalized and evaluated.

KEYWORDS: traffic psychology, driver improvement course, traffic offender course, traffic offender, behavioural change

\section{INTRODUCTION}

Traffic safety is one of the most relevant issues with respect to public health (Moller, 2009). Road traffic injuries are the eighth leading cause of death globally, and the leading cause of death for young people aged 15-29. Current trends suggest that by 2030 road traffic deaths will have become the fifth leading cause of death unless urgent action is taken.

Drinking and driving increases the risk of being involved in a crash, as well as the severity of the resulting injuries. Driving starts to be impaired at very low levels of alcohol consumption, with the risk of involvement in a crash growing rapidly as consumption increases (WHO, 2013). Alcohol is associated with $40 \%$ of fatalities and $20 \%$ of serious injuries that occur on the road, whereas only about $1 \%$ of all the kilometres driven in Europe are driven by drivers with $0.5 \mathrm{~g} / \mathrm{l}$ alcohol in their blood or more. Around 25\% of drivers have admitted to driving after drinking at least occasionally (TIRF, 1997). On any given night, it is estimated that one driver out of ten has been drinking and between $2 \%$ and $3 \%$ are over the legal limit. More recent research has drawn the attention of governmental bodies to a higher BAC; roughly $2 / 3$ of drivers who have been drinking and are involved in a fatal or serious crash have a BAC of $160 \mathrm{mg} \%$ or more. Compared to a sober driver, the crash rate of a driver with a BAC of $0.8 \mathrm{~g} / \mathrm{l}$ (still the legal limit in three EU member states) is 2.7 times that of sober drivers. When a driver has a BAC of $1.5 \mathrm{~g} / \mathrm{l}$ their crash rate is 22 times that of a sober driver. Not only does the crash rate grow rapidly with an increasing BAC, but the crash also becomes more severe. With a BAC of $1.5 \mathrm{~g} / \mathrm{l}$ the crash rate for fatal crashes is about 200 times that of sober drivers (ERSO, 2007). 
Speeding is a high-risk road use behaviour (e.g. WHO, 2015). The legal definitions of speeding include exceeding the posted speed limit or driving too fast for the current conditions. Speeding becomes aggressive driving when a vehicle's speed substantially exceeds the prevailing travel speeds of other vehicles (Goodwin et al., 2013). Speeding is common. About three-quarters of all the drivers in NHTSA's 2002 national survey reported that they had exceeded the posted speed limit on various types of roads. Specifically, $78 \%$ of the drivers reported speeding on interstates, $83 \%$ on non-interstate multilane roads, $78 \%$ on two-lane roads, and $73 \%$ on city streets during the past month. One-quarter to one-third of the drivers reported speeding on the various types of roads on the day of the interview (NHTSA, 2004).

A reduction in the average driving speed dramatically reduces the traffic accident rate and the number of road use-related injuries and fatalities (Nilsson, 2004). Driving is a self-paced task, i.e. the level of speed is the driver's choice. Hence, if we wish to enhance safety (and reduce the number of accidents, injuries, and fatalities), we need to ensure that drivers opt for a lower, or suitable, travel speed. It is therefore necessary to influence their behaviour.

There are several approaches to reducing traffic fatalities and injuries. Traditional strategies for reducing traffic fatalities focus on risk behaviours and their consequences by training safe behaviours (education), punishing risk behaviours (enforcement), or protecting drivers from the consequences of risk behaviours (road and vehicle design). Human error may account for about $90 \%$ of all traffic accidents (Rumar, 1985). It is reasonable to assume that it would be effective to apply psychological interventions in traffic safety measures to reduce traffic accidents. As discussed further in this paper, one of the psychological measures which work is driver offender courses. This measure has the potential to reduce the reoffending rate significantly, by about $50 \%$ for drunk drivers who participated in rehabilitation courses (Davies et al., 1999, in Bartl, 2003; Jacobshagen, 1997, 1998; Michalke et al., 1987; Schützenhöfer \& Krainz, 1999) and subsequently produce considerable public health benefits.

\subsection{Driver behaviour models and theories}

\subsubsection{Michon's driving model}

Within his approach, Michon defines a driver as: (1) an active road user, (2) a transportation consumer, (3) an active social being, and (4) a psycho-biological organism satisfying a number of basic needs (Michon, 1985). Moreover, he postulates three hierarchical levels of a road user's tasks, which are influenced by the different roles of a driver mentioned above. These three levels are not sequential, but can be active at the same time, and they can also influence each other.

The strategic level concerns general decisions about route and vehicle choice prior to driving. It includes the determination of trip goals and the consideration of upcoming costs or risks. Plans are influenced by general considerations about transport and mobility, but also by matters such as satisfaction and comfort (Michon, 1985).

At the tactical level, certain decisions concerning the driving task are made in real traffic. On the one hand, certain driving manoeuvres, such as obstacle avoidance, gap acceptance, turning, and overtaking, must meet the criteria set at the strategic level. On the other hand, the driving goals have to be adapted to the current traffic situation (Michon, 1985). It can be said that this second level is characterized by the formation and updating of the sub-goals. Decisions and cognitive processes have to adapt driving performance to meet the demands of the current traffic situation (Sommer et al., 2008).

The operational level deals with the implementation of driving manoeuvres and instantaneous reactions to the traffic environment such as braking to avoid collisions with obstacles (Michon, 1985). This level targets the control of the vehicle.

\subsubsection{The GDE Matrix}

The GDE Matrix, which describes driving behaviour on four hierarchical levels (Hatakka et al., 2003), is a well-known model of driving behaviour. It originated from driver training - hence the name "GDE Goals for Driver Education".

The levels used in the GDE Matrix are based on the driver model proposed by Keskinen (1996) and show many similarities to the Michon hierarchy (Michon, 1985). In comparison with Michon's driving model (Michon, 1985), the GDE Matrix is not only goal-oriented rather than behaviour-descriptive, but also includes a fourth level aiming at personal preconditions and ambitions, and in its latest version a fifth level dealing with cultural aspects (Peräaho et al., 2010):

- Level 1: Basic vehicle control (Operational level)

- Level 2: Mastery of traffic situations (Tactical level) 
- Level 3: Trip-related context and considerations (Strategic level)

- Level 4: Personal characteristics, ambitions, and competencies (General level)

- Level 5: Social environment

The first and basic level aims at the vehicle and how it is manoeuvred. This includes the basic knowledge on how to start the engine, change gears, etc., in order to be able to use the car in traffic in a proper way.

The second level focuses on the ability to master driving in traffic situations. A driver must be able to adapt his/her driving in accordance with the different demands of various traffic situations (e.g. junctions, overtaking, etc.). The ability to perceive hazards in traffic is also incorporated into this level.

The third level deals with considerations (why, where, when, and with whom the driving is carried out). Choices concerning the mode of transport, point in time of driving, or decision to drive under the influence of alcohol, fatigue, stress, etc. are included here.

The fourth level refers to personal motives and is connected with lifestyles, social background, gender, age, and other individual preconditions. All these factors have an influence on attitudes, driving behaviour, and accident involvement (Christ et al., 1999).

The fifth and highest level deals with the social environment, which includes culture, legislation, and group norms. The fourth and fifth levels influence each other: e.g., the culture influences the personal lifestyle, and persons with certain values seek special social groups (Peräaho et al., 2010).

On every level, the following three essential elements of driver training have to be built up: (a) knowledge and skills, (b) risk-increasing factors, and (c) self-evaluation.

\subsubsection{Road traffic as a system and as a culture} Building on an approach used in the organizational field, Gomes (1993) used the concept of road traffic culture, which implies that the way we drive has a history with its own language, symbols, myths, and rituals. In this context, driving reflects not only the way we drive, but also how each person is willing to be part of the same culture. It is not the the moment at which we obtain a driver's licence that makes us know how to behave on the road; our driving behaviour was shaped at a very early stage of our lives. Over the years we have developed a men- tal and "cultural" behaviour that helps us deal with the system (p. 25). If "the road scenario has a story with its own language, symbols, myths, and rituals" (Gomes, 1993, p. 25), it is through a qualification referred to as a "driver's licence" that a driver enters the system and can develop and use a set of behaviours that facilitate their sharing of the same values with those who are already part of the same system and the same culture (Silva, 2004). Thus, the following four essential elements of driver training have to be built up: (a) knowledge and skills, (b) risk-increasing factors, (c) self-evaluation, and (d) sharing culture and values.

\subsubsection{Risk-adaptation theory}

Koornstra (2009) created a risk-adaptation theory in which the psychophysical response and valence theory of choice behaviour proposed by Koornstra (2009) is applied to traffic behaviour. According to this model, risk behaviour in traffic is controlled by 'single-peaked' valences for fear conflicting with 'single-peaked' valences for arousal (Lewis-Evans, 2012). This means that the fear of an accident conflicts with the arousal caused by driving fast. Drivers seem to have an ideal level of arousal, as well as an ideal level of fear of an accident. Changes in one of them will impact on the other. Fear of an accident will be far from the ideal range if arousal increases, and arousal will be far from the ideal range if fear of an accident decreases. When these two dimensions are combined, an "indifference area" where there is low variability is created (Lewis-Evans, 2012).

\subsubsection{Risk homeostasis theory}

Wilde $(1978,1994)$ assumes that there are subjective and objective components of risk perception. Risky behaviour while driving is seen as a homeostatic result of the interplay between a subjectively accepted degree of risk on the one hand and the objective traffic situation on the other hand. The relationship between these subjective and objective components is based on a cost-benefit equation. The theory follows the idea that individuals accept a certain degree of risk in exchange for an expected benefit (which the intended action is expected to provide). Thus, individuals in risky situations compare the current degree of risk with their own accepted reference values. If the objective degree of risk increases during a certain situation (e.g. a certain driving manoeuvre), the person will adapt their behaviour to keep their subjective reference value constant. Furthermore, the 
model assumes that in the face of an objective risk individuals tend to differ significantly with regard to the subjective degree of risk that they are prepared to accept (Wilde 1978, 1994).

\subsection{Behaviour, performance, and personality as factors contributing to crashes}

Although $95 \%$ of road accidents are co-caused by the human factor (e.g. Praxenthaler, 1985), it is still impossible to determine the correlations and significance of individual human attributes, behavioural patterns, and qualities which are responsible for the accidents because of the immense number of relevant and intervening effects (Risser, 1997; Sommer, 2008). The relationship between the rate of road accidents and drivers' personalities has not been sufficiently explained and there are authors who put the majority of psychological qualities in doubt in terms of their effects on the road accident rate (e.g. Burns $\&$ Wilde, 1995). Research has emphasized personality factors as contributors to risky driving and accident causation. Despite the large body of studies, their findings have been either conflicting or of little importance (Ranney, 1994). The relationship between skills, behaviour, and accident involvement is complex, and it is a challenge for psychology to provide a better understanding of how human factors and psychological mechanisms are related to this (Elander et al., 1993). However, this does not imply a lack of driver skills, personality, and abilities to predict accidents. Conflicting results can arise from theoretical or methodological shortcomings (Lajunen \& Summala, 1997).

The importance of behaviour in the prevention of vehicular accidents has been extensively documented (e.g. Elander et al., 1993; Parker et al., 1995) and has led to many attempts to encourage a variety of safe driving behaviours (e.g. Juhnke et al., 1995; Martinez, 1997). The emphasis has shifted from performance-related capabilities to willingness to take risks. Evidence indicates risk-taking as a major factor underlying a high collision risk (Jonah, 1986). Unsafe drivers are not necessarily those with low skills. Skilled drivers who engage in risky activities such as speeding might be even more dangerous.

\subsection{Risky driver behaviour}

A high-risk driving behaviour is any behaviour linked with a significantly higher likelihood of being in- volved in a crash. High-risk driving behaviours are numerous and often interrelated. However, it appears that four driving behaviours are universally depicted as major risks:

\section{1. speeding}

2. driving under the influence of alcohol and drugs

3. non-use of safety belts and child restraint devices

4. running red lights or stop signs

Other such behaviours that are frequently reported include:

1. driver's distraction and inattention

2. driver's fatigue

3. aggressive driving

4. driver's stress, anxiety, and anger

5. work-related road risk

An increasing body of literature shows that there is a considerable overlap between high-risk driving behaviours (e.g. CCMTA - Canadian Council of Motor Transport Administrators, 2010). The "drinkdriving - non-use of seat belts" link is well established. For instance, roadside surveys have shown that non-users of seat belts are twice as likely to have been legally impaired. Indeed, the profile of fatally injured drivers who did not use their seat belts is - to a large extent - similar to those who died after drinking and driving: weekend, night-time, male, etc. Other overlaps have been observed between speeding and running red lights and running red lights and non-use of seat belts. The exact magnitude of highrisk behaviours overlapping is not known. It cannot be assumed that they are engaged in by the very same individuals, but overlapping appears clearly prevalent (Canadian Council of Motor Transport Administrators-CCMTA, 2010).

Given the scope of this paper, we will continue by discussing in more detail the first two risky behaviours - speeding and driving under the influence of alcohol and other drugs.

\subsubsection{Speed is a central road safety issue}

In relation to road safety, speed affects (a) the risk of being involved in an accident and (b) the severity of an accident. In general, the higher the speed, the higher the risk of an accident and the more severe the consequences of an accident. In fact, speed is involved in all accidents: no speed, no accidents. Speed has been found to be a major contributory 
factor in around $10 \%$ of all accidents and in around $30 \%$ of fatal accidents (SafetyNet, 2009). Both excess speed (exceeding the posted speed limit) and inappropriate speed (going faster than the prevailing conditions allow) are important accident causation factors. In addition, speed generally has a negative effect on the environment, but a positive effect on travel time. The negative effects are mainly a societal problem and are hardly noticed by individual drivers; individual drivers, on the other hand, particularly notice the positive effects. On the evidence of the work by Nilsson (2004) in Sweden, a change in average speed of $1 \mathrm{~km} / \mathrm{h}$ will result in a change in accident numbers ranging between $2 \%$ for a $120 \mathrm{~km} / \mathrm{h}$ road and $4 \%$ for a $50 \mathrm{~km} / \mathrm{h}$ road. Despite the fact that the vast majority of drivers exceed the speed limits, excessive speeding $(>20 \mathrm{~km} / \mathrm{h}$ above the limit) is concentrated among around $15 \%$ of the driving population. The relationship between speed and accident risk is a power function: with increasing speed, the accident risk increases more as the absolute speed is higher.

\subsubsection{Driving under the influence of alcohol and other drugs}

About $25 \%$ of all road fatalities in Europe are alcoholrelated, whereas about only $1 \%$ of all the kilometres driven in Europe are driven by drivers with $0.5 \mathrm{~g} / \mathrm{l}$ or more alcohol in their blood. As the Blood Alcohol Concentration (BAC) in the driver increases, the crash rate also rises. The increase in the crash rate that goes with increasing BAC is progressive. In com- parison with a sober driver, the crash rate of a driver with a BAC of $0.8 \mathrm{~g} / \mathrm{l}$ (still the legal limit in three EU member states) is 2.7 times higher than that of sober drivers. When a driver has a BAC of $1.5 \mathrm{~g} / \mathrm{l}$, their crash rate is 22 times higher than that of a sober driver. Not only does the crash rate grow rapidly with increasing BAC, the crash also becomes more severe. With a BAC of $1.5 \mathrm{~g} / \mathrm{l}$ the fatal crash rate is about 200 times higher than is the case with sober drivers (European Commission, 2015).

Some authors (e.g. Kloeden et al., 1997) have noted that the increased risk as a result of driving at speeds of more than $10-20 \%$ above the average for the road is similar to the increased risk resulting from driving with a BAC within the drink-driving limits in the two countries to which the references relate (i.e. $0.5 \mathrm{~g} / \mathrm{l}$ and $0.8 \mathrm{~g} / \mathrm{l}$ respectively). This is based on empirical research in Australia.

\subsection{Risky driver groups}

Evidence shows that personal characteristics such as the driver's experience and skill (Lim \& Dewar, 1989) gender (Briem \& Hedman, 1995), and personality (Evans, 1991) can affect driving performance, including driving safety. In fact, healthy young people are more likely to be involved in accidents than others.

Gender has consistently been reported as relating to risk behaviour, i.e. males are more willing to take risks than females. It has been argued that the evolutionary process has made it necessary for males to take

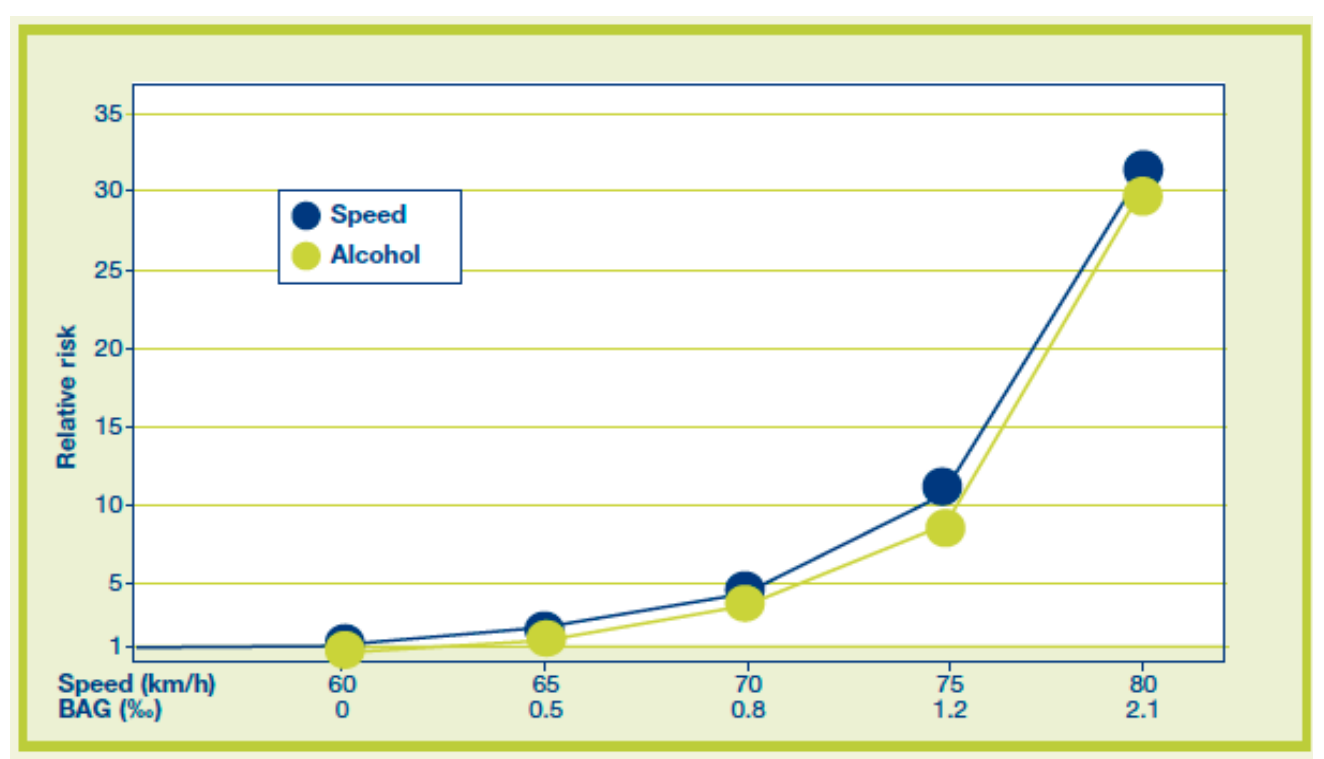

Figure 1: The comparison of increased risk for speeding and drink driving (Kloeden, McLean, Moore, \& Ponte, 1997) 
risks and that this tendency is therefore an adaptation (Turner \& McClure, 2003). Yagil (1998) reported that male drivers, particularly younger individuals, expressed a lower motivation to comply with traffic rules. She also found that males perceived traffic violations as less dangerous than females did.

The high-risk driver profile established by the Traffic Injury Research Foundation (TIRF) has revealed some prominent characteristics: young, male, employed, with low to moderate income, engaging in other safety-compromising behaviours, thrill-seeking, aggressive, and with a record of previous traffic violations and crashes (Beirness \& Simpson, 1997).

It appears there are three high-risk groups (Vèzina, 2001):

\section{1. young drivers $(<25$-year-olds)}

2. hard-core drinking drivers

3. drivers with previous violations and crashes

The 18-24-year-old group represents one in eight drivers but is involved in one in every four casualty crashes. Their crash involvement risk is consistent with their traffic violation record: a similar proportion of $25 \%$ of the total. The hard-core drinking driver group comprises high-BAC (.15) or repeat offenders who represent roughly two-thirds of the drivers who have been drinking and are involved in fatal or serious crashes. The main characteristic of the hardcore drinking driver is a common diagnosis of alcohol abuse or dependence. Previous violations and/or crashes can be used to identify a high-risk driver. As the number of previous events (violations or collisions) increases, the likelihood of future involvement in a fatal crash also increases. Within a two-year period, one event is associated with a 1.5 risk factor and two events with a 2.5 risk factor, while three events represent a 4.5 risk factor in terms of involvement in a fatal crash (Vézina, 2001).

\subsection{Enforcement and rehabilitation: some existing models}

Driver rehabilitation courses came into being in the USA in the 1970s. Not much later, driver improvement courses were implemented in Germanspeaking countries in Europe. These courses were dedicated to drunk drivers, speeding offenders, and drivers who committed other serious offences. In the 1990s other European countries finally adopted these programmes. Their relevance lies in the reintegration of high-risk drivers. Traffic violators show a lack of positive attitudes concerning social responsibility rather than a lack of skills. The main focus of the rehabilitation courses is to promote self-reflection as a starting point to self-awareness about risk and to a change in wrong attitudes related to, for example, drunk driving. The rehabilitation programmes are defined as "systematic measures for traffic offenders" - in particular drunk drivers and speed offenders - intended to change their behavior in order to prevent further offences and for them to keep or regain their driver's licences" (Bartl et al., 2002, in Bartl, 2003).

Two types of criteria may be used to evaluate driver rehabilitation courses: hard criteria and soft criteria (Bartl, 2003). The hard criteria focus on the participants' rate of reoffending. The soft criteria focus on process evaluation. In terms of hard results, some investigations show reductions in the reoffending rate by about $50 \%$ for drunk drivers who participated in rehabilitation courses (Davies et al., 1999, in Bartl, 2003; Jacobshagen, 1997, 1998; Michalke et al., 1987; Schützenhöfer \& Krainz, 1999). Tthese results may suggest changes in participants' attitudes and behaviour.

Bartl (2003) also states that success can be achieved when courses take into account participants' deficits or needs. In summary, it is suggested that successful courses share certain characteristics: the group is small (about 10 participants), the duration is not too short (varying from three to ten sessions distributed over three to ten weeks), and the focus is on self-reflection together with discussion and psychotherapeutic elements.

The EU Andrea project (Bartl et al., 2002) yielded feedback from 1375 participants and 60 course leaders about courses in Austria, Belgium, France, northern Italy, and the Netherlands. $68.8 \%$ of the French participants and $89.2 \%$ of those from the other countries stated that the course was useful in trying to avoid future violations. $75 \%$ of the participants stated that the course was useful in terms of its content. $8.5 \%$ said they would not reoffend because of the aversive nature and the cost of the course. The pre-course results showed that $51 \%$ of the participants referred to the usefulness of the content and $18 \%$ referred to the aversive nature and the cost of the course. The psychological and physiological effects of alcohol and speeding units were pointed out by the participants as more 
interesting and useful than those on the acceptance of social norms. The author states that these results are evidence of the participants' problems: their acceptance of social norms and legal rules. Consequently, Bartl (2003) highlights the importance of reintegrating drivers into the system and promoting their individual social responsibility. The results also show a preference for discussioncentred methods on the part of both participants and course leaders. The participants preferred to find solutions by themselves and discuss unpleasant subjects rather than avoiding them. According to Bartl (2003), these results suggest a preference for the self-reflection method instead of teaching. Following the completion of the course, the participants seemed to attribute greater importance to the discussion of unpleasant and personal subjects than before the course.

Subsequently, another EU project called DRUID (2006 - 2010) focused on driver rehabilitation, especially for DUI offenders (WP 5 - Rehabilitation). The review conducted under this project (Boets et al., 2008) focused on the effectiveness of driver rehabilitation (for DUI/DUID offenders) and identified 61 studies on the topic. An average reduction rate in levels of reoffending by $45.5 \%$ (36 studies and 2 reviews) was noted, although a large variation in the reoffending reduction rates was observed (15\%-71\%). In general, the interventions received positive participant feedback and in addition to that, led to individual changes (such as enhanced knowledge and a positive attitude).

Some authors (e.g. Bukasa et al., 2009) recommend supporting the implementation of driver rehabilitation for non-dependent DUI (Driving under the influence of alcohol) and DUID (Driving under the influence of illicit drugs) offenders in European countries. Driver rehabilitation for non-dependent DUI/DUID offenders should be an integral part of a comprehensive system of countermeasures. Common guidelines for legally regulated driver rehabilitation should be established. The following recommendations are suggested:

- addiction treatment for offenders addicted to alcohol or drugs;

- traffic safety/driving licence/intoxicated driving-related modules in addiction treatment;

- legal regulation of DR participation;

- formal criteria to assign DUI/DUID offenders directly to DR or to driver assessment;
- driver assessment necessary in the event of suspicion of addiction or a high risk of reoffending;

- driver assessment carried out by means of a multidisciplinary approach using scientifically proven measuring tools;

- evaluation studies on a regular basis for all programmes.

Stanton et al. (2007) analyzed the effects of a combined use of a model for the identification of and response to the dangers of coaching drivers in knowledge, skills, and attitudes. "Coaching is designed to develop the awareness and responsibility of the person being coached. These are all vital components in encouraging safe driving" (Hermes Project, 2010, p.7).

The IPSGA model has five categories: Information, Position, Speed, Gear, and Accelerate (Stanton et al., 2007). The study included three groups: the first was subjected to a full coaching programme (experimental group), the second was only subjected to observation, getting no coaching or feedback programme (control group), and the third was subjected to neither observation nor coaching (control group). The results showed that the group receiving coaching recorded an improvement in terms of knowledge, skills, and attitudes. Awareness showed an improvement in terms of quantity, type, and structure. As for skills, the drivers in the experimental group showed a larger number of appropriate skills and smaller number of inappropriate skills. The improvement in attitudes was manifested by a greater internal locus of control and a lesser external one. Thus, the authors conclude that coaching brings more advantages than other practices, experience or training do (Stanton et al., 2007).

\section{MATERIAL AND METHODS}

\subsection{About TPI}

This work was carried out within Traffic Psychology International (TPI). TPI is a framework for cooperation between European traffic psychologists aimed at increasing the influence of traffic psychology within the field of traffic safety across Europe and beyond. It was established in 2010 as a kind of "task force", with the idea being to support each other and have the chance to work on the international and national policy levels. 


\subsection{Data collection and data analysis}

\subsubsection{Data collection}

Data was collected in eleven European countries during the year 2014, using a questionnaire developed for this purpose. For every country at least one expert (a psychologist working in the field of traffic safety) was asked to fill in the questionnaire in the course of information exchange between the countries. All experts were recruited from the Traffic Psychology International group. The participating countries, Austria, Belgium, the Czech Republic, Estonia, Germany, Hungary, Luxembourg, Portugal, Spain, Slovakia, and the United Kingdom, were selected on the basis of experts and information being available.

\subsubsection{Questionnaire}

The questionnaire contained 21 open questions aimed at collecting detailed information about different types of driver improvement courses. For each type of course one separate questionnaire had to be answered. Inspired by other similar questionnaires used in some EU projects, the questionnaire was developed by an expert group within TPI. This questionnaire was piloted within a small group of traffic experts and finalized on the basis of their comments. The final version was distributed on a personal basis during a meeting of the research group.

\subsubsection{Data analysis}

The data analysis followed standard rigorous data analysis approaches. The data was analyzed systematically using a modified version of the Editing Analysis Style. Our study applied thematic analysis as a tool for pattern recognition across qualitative data. Each country and each type of driver improvement course was analyzed separately. For the purposes of the qualitative analysis the texts were further treated following the sociological tradition of qualitative data being regarded as a window into human experience.

\section{RESULTS}

In this section we present the results of the analysis of the data on driver improvement courses collected from 11 European countries. The information is structured according to the different countries, listed in alphabetical order. The structure of the data follows that of the questionnaire used to collect the data. Finally, a summary of common approaches and groups of countries using the same approaches is presented.

\subsection{Detailed analysis of each country}

Austria: A driver improvement (DI) course for deviant drivers and DI courses for alcohol offenders are provided by institutes of traffic psychology authorized by the Ministry of Transport Innovation and Technology. In both cases, the course leaders are psychologists with additional training in traffic psychology. Both courses involve specific preventive interventions to avoid reoffending by exerting an influence on the participants' attitudes and behaviour. The participants are to be positively influenced to increase their traffic-related risk awareness and to behave more safely and have regard for others. Each of the courses costs EUR 495. This price is set by the law and the clients pay it themselves. The target group of the DI courses for alcohol offenders consists of drunk drivers with at least $1.2 \mathrm{~g} / \mathrm{l} \mathrm{BAC}$, repeated drunk drivers with less than $1.2 \mathrm{~g} / \mathrm{l} \mathrm{BAC}$, and novice drivers with probationary licences who were caught driving with more than $0.1 \mathrm{~g} / \mathrm{l} \mathrm{BAC}$. The target group of the courses for deviant drivers is speeders (drivers who committed two speeding offences by being more than $40 \mathrm{~km} / \mathrm{h}$ over the limit in urban areas or more than $50 \mathrm{~km} / \mathrm{h}$ over the limit in rural areas within two years and novice drivers exceeding the speed limit by more than $20 \mathrm{~km} / \mathrm{h}$ in urban areas and more than $40 \mathrm{~km} / \mathrm{h}$ in rural areas), as well as novice drivers with certain other offences. Furthermore, there are DI courses based on a demerit point system (DPS). Every driver with two points is required to undergo DI training (in Austria you get one point per offence). Also available are DI courses focused on driving under the influence of drugs, especially designed for novice drivers. The course type is dependent on the offence; not all of them are DI courses. DI courses in Austria are paid for by the client.

Belgium: DI courses focused on alcohol offenders, traffic safety, illegal drugs, road rage, "mopeds", and speed are provided by the Belgian Road Safety Institute (BIVV-IBSR). In all cases, the courses are conducted by individuals trained in traffic psychology, traffic safety, group animation, and behavioural change processes. They are psychologists, but also criminologists and social workers. DI courses for alcohol offenders are intended for the participants to gain insights into the influence of alcohol on their driving tasks and into their own alcohol consumption, to understand the law and the alcohol limits, and to make a plan to avoid reoffending. The DI courses addressing the issues of traffic safety, 
road rage, and speed are intended to help the participants analyze their attitudes while driving and understand the law and the consequences of violating it (in the case of traffic safety), the impacts of their acts (in the case of road rage), and the impact of speed (in the case of speed), increase their risk perception, and make a plan to avoid reoffending (in the case of road rage, using the analysis of their previous behaviour). The DI courses concerned with illegal drugs are intended for the participants to gain insights into the effects of illegal drugs on their driving tasks and into their own drug consumption, to understand the law and the consequences of violating it, and to make a plan to avoid reoffending. The DI courses for "mopeds" are intended to help the participants analyze their attitudes while driving, understand the consequences of their behaviour, and increase their risk perception. In the first four cases, the courses cost about EUR 800, with the government bearing these costs. The DI courses for "mopeds" cost about EUR 200, and the government bears the costs in this case too. The DI courses that focus on speed cost about EUR 390, which has to be paid by the participants. The target group of the DI courses for alcohol offenders comprises all drivers who commit the offence of driving under the influence of alcohol and those who cause an accident while impaired. As regards the DI courses concerned with traffic safety, the target group is all drivers who committed a serious violation without the involvement of alcohol or illegal drugs. The target group of the DI courses dealing with illegal drugs is all drivers who commit the offence of driving under the influence of illegal drugs and those who cause an accident while impaired. The target group of the DI courses for "mopeds" comprises young people who were riding a tuned moped. The target group of the DI courses on "road rage" is all drivers who commit a serious act of aggression towards another road user - acts of assault and/or battery or serious threats. Finally, in the DI course on speed, the target group comprises people with serious speeding offences (more than $30 \mathrm{~km}$ above the limit).

Czech Republic: There are three types of DI courses in the Czech Republic: courses for drivers in prison, courses for alcohol offenders under the supervision of the Probation Service, and courses for drivers with issues referred by traffic psychologists (usually the precondition for a person to pass psychological assessment as fit to drive). The target groups of the programmes comprise drivers with serious offences who were sent to prison for at least six months (six months is required for organizational reasons; the programme is delivered twice per year), alcohol offenders, or anybody who seems to be an unsafe and unreliable driver according to the results of a traffic psychological assessment (TPA). All the programmes are voluntary; drivers can refuse to participate. The programmes are offered to selected drivers by the Prison Service, the Probation Service, or traffic psychologists. The duration of the courses varies from 18 to 50 hours. The costs range from EUR 1000 to EUR 2000 and are covered by the government. The programmes started on 1 January 2010 . They are provided as part of a pilot project and are financed by the competent ministry and money earmarked for research. The real-life implementation is planned in upcoming years. In 2017 DI courses are still undergoing pilot realization.

Estonia: A DI course named "Follow-up Training", for novice drivers with a licence issued for a probationary period, is already being implemented in Estonia. In the future, a DI course for DUI drivers will be obligatory. DI courses are implemented by a higher education institution holding a training licence issued by the Ministry of Education and Research. There are certified traffic psychologists, working with all offenders, and driving school teachers, working with first-time offenders (with the exception of those charged with driving under the influence). The course leaders must take at least 120 lessons of basic training for the providers of Follow-up Training for traffic offenders and must be recognized by the Estonian Road Administration as Follow-up Training providers. The Follow-up Training course is intended to promote drivers' law-abiding behaviour in traffic through a counselling process in order to restore safe traffic behaviour that takes other road users into consideration. The cost of Follow-up Training varies (starting from EUR 200) and is covered by the clients and from public funding (the government). The target group of these DI courses comprises offenders who hold a provisional licence, valid for two years, and if the driver violates the traffic regulations during this period and their driver's licence is withdrawn, they are required to take a follow-up course. Another target group of Follow-up Training consists of drivers convicted of driving under the influence. DUI offenders have to undergo this course before having their licence reinstated. 
Germany: DI courses for novice drivers are carried out by authorized institutes. The course leaders are psychologists with additional training in traffic psychology. The course involves a specific preventive intervention aimed at avoiding re-offending by promoting change in the participants' attitudes and behaviour. The participants are to be positively influenced to increase their traffic-related risk awareness and behave more safely and have regard for others. The course costs between EUR 250 and EUR 350, paid by the client. The price depends on the provider; there is no fixed price. The target group of the DI courses comprises novice drivers holding a probationary licence (there is a two-year probation period) who committed the offences of driving under the influence of alcohol ( $>0.0 \%$ o BAC) or under the influence of drugs/medication. There are three 180-minute sessions and a 60-minute preliminary talk in groups of up to 12 participants.

Hungary: The driver rehabilitation system in Hungary consists of seven different programmes, which are applicable in different variants. The candidates are required to undergo a so-called "exploratory" phase, which has three parts: (1) a theoretical test (a computerized test containing a set of questions on traffic rules); (2) a practical test (driving trial), and (3) a psychological interview (without performance testing). The aim of the exploration is to determine each person's individual problems in order to assign them to one of the seven rehabilitation programmes. The exploration team comprises at least three professionals qualified to run all the programmes (qualified psychologists and transport education experts registered as rehabilitation course providers). The seven DI courses are: (1) DI for improving the knowledge of traffic rules; (2) DI for improving driving practice; (3) DI for the alteration of wrong traffic attitudes; (4) DI for drivers causing death or serious/permanent injury by dangerous driving; (5) DI for slightly drunk drivers; (6) DI for moderately drunk drivers, and (7) DI for heavily drunk or repeated drunk drivers. All the courses can only be delivered by a person registered as a rehabilitation course provider with the National Transport Authority (NTA) Central Office. The course leaders are traffic psychologists (DI 3-7), traffic education professionals (DI 1, 3), and driving instructors (DI 2). The courses cost between EUR 135 and EUR 480, depending on the course. The course fees are covered by the clients.
The content depends on the course type (e.g. increasing self-knowledge and learning self-control strategies).

Luxembourg: There are five different driver improvement courses in Luxembourg. The first one is a one-day safety training course - Stage obligatoire pour conducteurs novices. A programme for novice drivers at the CFC (Centre de Formation pour Conducteurs) in Colmar-Berg has been available since 1 July 1995. Within two years of acquiring their driving licence (on probation), novices must take this obligatory course; driving experience of at least $3000 \mathrm{~km}$ is recommended. No definite licence will be issued without that course within two years! In the event of any serious traffic offence the trial stage is prolonged or the licence is suspended. The learningby-doing method is used: theory and practice lasting seven hours. There are six to ten clients per instructor/trainer (no psychologist). The clients pay from EUR 190 to EUR 210.

The second one is a voluntary three-point sensitization course (within the demerit point system) (one day, seven hours, max. 12 participants). Drivers can recover three points in the DPS for every three years. The participants are taught to recognize their mistakes and avoid them in the future. The course consists of three hours of practical demonstrations led by an instructor (CFC) and four hours of psychological training and counselling by a psychologist (IPG). The cost is EUR 287, paid by the clients.

The third one is a 12-point rehabilitation course (five days/four-six weeks, 18 hours), which is obligatory for drivers to recover their driving licence after a one-year suspension, and comprises three components: two on-road audits, three hours of practical demonstrations conducted by instructors, and 12 hours of psychological sessions in four days (the topics to be covered include motivation for and compliance with taking responsibility and individual safety goals, individual behaviour analysis, abuse of alcohol, drugs, and medication, emotional and behavioural deregulation, and speed and the related consequences/risks). The cost is EUR 603 and is covered by the clients.

The fourth one is a two-day rehabilitation course, "Stage de rehabilitation", for selected drivers who committed a serious offence and were sentenced by one of two courts of justice. This stage thus replaces prosecution. The courses are led by a psychologist and another specialist in road safety. 
The last one is called IPSM ${ }^{\circledR}$-CAR-COP-SIR. It involves individual or group psychotherapy offered as a complementary intervention for clinical cases after the voluntary or obligatory courses or as a preventive measure for patients at risk of their driving licence being suspended. The cost of this 40-lesson (each lesson lasting 50 minutes) course is covered by the clients and depends on their income.

Portugal: The courses, determined by DecreeLaw No. 265/A/2001-Article 142-I-A Series No. 226, the Road Code - Law No. 72/2013, and Legislative Order No. 4/2003, are implemented by the National Road Safety Authority (ANSR - the Ministry of Internal Affairs). Portuguese Road Safety (PRP) is a non-profit public utility association, appointed by the ASNR as the agency responsible for the courses. PRP offers courses all over the country, mainly in district capitals. The course leaders are clinical psychologists. The courses are intended to change drivers' behaviour in order to prevent reoffending. The objective of this specific training is to encourage people to adopt responsible behaviour. An intervention by a clinical psychologist with experience of group dynamics/management is justified by the need to deal with and manage group phenomena and the ability to identify drivers without behavioural competences for driving. The topics to be covered include alcohol, drugs, speed, and various dangers (other offences). The content is related to the type of infringement. The cost of the courses, EUR 175, is covered by the offenders. The target group comprises drivers found guilty of an infraction who have to accept the decision from the National Road Safety Authority (ANSR) after the infraction. The agency only specifies the frequency of training sessions as a measure for suspending the disqualification. In order to comply with the ban on driving for the period specified in the decision from the ANSR, drivers have two options: to submit their licence to the Territorial Command/Detachment Traffic GNR or the Metropolitan Command/ District Chamber of Offences Security Police or attend a training course and continue to drive without having to temporarily return their licence.

Slovakia: In Slovakia there is one type of driver improvement course for those caught driving under the influence of substances. This DI programme has to be completed by everyone with any level of BAC or the presence of any drug or addictive substance in the blood. The main objective of the programme is to avoid reoffending by exerting an influence on the participants' attitudes and behaviour. The participants are to be positively influenced to increase their traffic-related risk awareness and behave more safely and have regard for others. The driver rehabilitation course consists of four sessions (of three hours) + max. 60 minutes of individual interviews. The intervals at which the group sessions take place are at least seven but not more than 14 calendar days. The courses are provided by psychologists with additional training in traffic psychology (certification for traffic psychology) under the aegis of certified traffic psychology institutes. In 2014 there were 172 of those in Slovakia.

The intervention was introduced in November 2011. The cost is EUR 250 and is covered by the clients.

Spain: A driver improvement course named INCOVIA - Intervention and Awareness Programme on Road Safety Reeducation - is carried out at 220 Spanish driving schools that are holders of a special licence, which is awarded by the Traffic General Directorate for the implementation of the INCOVIAINTRAS intervention. The Research Institute on Traffic and Road Safety of the University of Valencia is responsible for training the trainers for the programme. The course leaders are psychologists who have completed an additional training programme in traffic psychology (16 hours) and driver instructors with additional road safety training ( 80 hours). INCOVIA is intended to raise awareness of the serious consequences of road accidents (individual, economic, and social harm), make the drivers aware of their own responsibility for dangerous driving, and change their behaviours and attitudes to become more considerate towards other road users. The INCOVIA course costs EUR 205.30 (partial recovery courses) or EUR 386.45 (total recovery courses). The offenders bear these costs. The target group of INCOVIA comprises all drivers who lose some or all of their licence points by committing one of the following offences: exceeding the speed limit; driving without a child restraint system, seat belts, or helmet; driving under the influence of alcohol or drugs; refusing to submit to alcohol or drug testing; driving recklessly, driving on the wrong side of the road, or participating in illegal races; exceeding the stipulated driving time by more than $50 \%$ or cutting rest periods by more than $50 \%$ (applicable to professional drivers only); using anti-radar devices or manipulating tachographs or speed limiters; driving vehicles on 
prohibited highways, driving a vehicle without a valid driver's licence or excessive vehicle occupancy (in excess of $50 \%$ of the number of authorized seats, excluding the driver; failure to respect the right of way, stop signs, and yield or red lights; overtaking improperly or endangering or limiting other road users, including cyclists; hindering or preventing another vehicle from overtaking by increasing speed; driving backwards on a motorway or freeway; ignoring police signals; discarding on the road or nearby any objects that could cause a fire or accidents or impede traffic; failure to keep a safe distance; making a U-turn in areas where it is not allowed; riding a moped or motorcycle with a passenger under 12 , and driving while using mobile phones or headphones or other devices that may distract attention.

United Kingdom: There are several courses that are offered to drivers as an alternative to prosecution. Available in England, Wales, and Northern Ireland (Scotland does not provide these courses), they include: National Speed Awareness Course, National Speed Awareness Course 20mph, National Driver Alertness Course, National Ride Course, National What's Driving Us? Course, and National Driving 4 Change Course. An online course - Your Belt Your Life - for seat-belt offenders is also available. There is one course - the Drink Drive Rehabilitation Scheme (DDRS) - that is offered to convicted drivers in the entire UK to reduce the duration of their ban. All the courses are voluntary. The national courses are accredited by the NDORS - the National Driver Offender Retraining Scheme - and commissioned by police forces. Traditionally, these courses have been run by road safety officers affiliated with local government authorities and in some areas the police have commissioned the local government to run the courses.

All NDORS courses are for drivers who have committed an offence that has not resulted in serious harm or injury. While each has its own set of specific objectives, they are all aimed at helping keep communities safer by motivating and enabling the driver not to reoffend. Drivers are offered NDORS courses by the police as an alternative to prosecution. They can choose to attend a course or to be prosecuted, either with a fixed penalty notice, or they may choose or be required to attend court. A driver is eligible to complete each course only once in a three-year period (which is the same period of time as that for which the licence demerit points last). The duration of the courses is three to seven hours, with the exception of DDRS, which takes 16 hours. Different courses require different amounts to be paid, generally about EUR 120-200. DDRS costs a maximum of EUR 400. The drivers bear the costs.

\subsection{Groups of countries with the same approaches}

Looking at common DI approaches in Europe, the following conclusions have been drawn:

\section{Course type}

The most common driver improvement courses are the ones for deviant drivers (dealing with the drivers' bad habits), for drivers who drove under the influence of alcohol, and the ones who drove under the influence of drugs. DI for drunk drivers is the most widespread. This course type is provided in 10 out of the 11 countries - Austria, Belgium, Estonia, Germany, Hungary, Luxembourg, Portugal, Slovakia, Spain, and the UK. DI for deviant drivers is provided in eight out of the 11 countries, namely Austria, Belgium, Hungary, Luxembourg, Portugal, Slovakia, Spain, and the UK. The third common DI course in Europe is the one for drivers who drove under the influence of drugs. Such courses are provided in Austria, Belgium, Estonia, Germany, Portugal, Spain, and Slovakia, which makes seven out of the 11 countries. Beside these three "main types" of DI, there are others which are occasionally conducted in various countries (e.g. DI for improving knowledge of the traffic rules, DI for drivers in prison, DI for drivers of tuned mopeds, and other course types).

\section{Course modality}

Driver improvement courses are obligatory in seven out of the 11 countries (Austria, Germany, Hungary, Estonia, Spain, Luxembourg (12-point DPS course), and the UK. Three out of the 11 countries offer optional DI courses. These countries are the Czech Republic, Luxembourg (3-point DPS course), and Portugal.

\section{Course leaders}

Concerning course leaders, it should be mentioned that it is hard to give a short overview of who is responsible for DI programmes. This is due to the various course types in different EU countries. In general, we can summarize by stating that psychologists are either course leaders themselves or are at least responsible for the training of course leaders. In every 
participating country, with the exception of the Czech Republic, Belgium, and the UK, there is at least one course type for which it is mandatory for it to be conducted by a traffic psychologist or psychologist. In the Czech Republic and Belgium, for every course type the course leader can be a psychologist, but it is not required. The UK has not deployed psychologists for conducting DI programmes, but psychologists are involved in trainer-training programmes.

\section{DISCUSSION}

The limitation of this study is the number of countries which provided data for the research. Out of the 28 EU countries, 11 provided data, i.e. a little more than one-third of all the countries. We cannot assume that the reporting countries are representative of all the other countries.

According to the theory of the GDE Matrix, especially its higher levels, only skills and knowledge by themselves are not sufficient for safe driving. As driving is a self-paced task, motivational aspects (beliefs, norms, values, lifestyle, and cultural and other social influences) seem to be crucial. Therefore, an effective DI course must tackle motivation-specific issues, i.e. promote self-reflection, self-monitoring, awareness, and responsibility, rather than focusing on delivering information only. Importantly, traffic psychology as a background theory and traffic psychologists as professionals must be taken into account.

It should be mentioned that DI has limited success for specific clients. Driver improvement courses are not intended for drivers who are problem drinkers or are substance-dependent according to the DSM IV or ICD 10 criteria. For drivers with a diagnosed substance dependence or problem drinking, specific psychotherapy would be more suitable. As the first step, the legal basis for conducting special therapies for problem drinkers or frequent repeat offenders with the aim of their reintegration into active traffic participation must be established by the governments on the local and EU levels.

\section{CONCLUSION AND RECOMMENDATIONS}

General recommendations for the implementation of effective driver improvement courses are that all courses must be evaluated (to provide evidence of their effectiveness) and it must be ensured that there are no negative side effects and that they yield a public benefit. Skills training without understanding leads to risky behaviour. It increases confidence without competence. There is clear evidence that driver education can lead to an increase in crash involvement (Mayhew \& Simpson, 2002; Roberts \& Kwan, 2001; Vernick et al., 1999). To conclude, as stated above, all driver improvement courses must be: driven by theory and evidence; designed to avoid overconfidence, increased risk exposure, and the normalization of risky behaviour, and evaluated.

Penalties for excess alcohol differ across member states, but generally range from heavy fines to prison sentences. They are often combined with periods of disqualification or rehabilitation courses. In many countries driver improvement courses have been available to offenders for a number of years, those relating to drink driving being the most common (ETSC, 2008).

On 26 October 2006, the European Commission published a Strategy on Alcohol-related Harm Reduction. The reduction of injuries and deaths resulting from alcohol-related road traffic accidents is mentioned as one of the priorities (Chapter 5.2). The document focuses on preventing and curtailing heavy and extreme drinking patterns, including underage drinking, and some of their most harmful consequences, in particular alcohol-related road collisions. Driver improvement courses are not mentioned explicitly, although a positive attitude towards this measure is obvious: "Examples of efficient national policies rely on the introduction and enforcement of frequent and systematic random breath testing, supported by education and awareness campaigns involving all stakeholders. A combination of strict enforcement and active awareness raising is a key to success." (European Commission, 2006).

The data presented in this article makes it clear that driver improvement (DI) courses are a well-established measure which tackles problems posed by highrisk driving, especially driving under the influence of alcohol or other drugs and speeding. In all the EU countries represented in this research (eleven countries), at least some driving improvement courses have been implemented. In more than half of the countries they are very well-established and their effects are validated. The Czech Republic is an example of a country at the other end of the spectrum, where DI courses are being implemented within a pilot period before they are incorporated into the system of law. 
Taking into account the fact that there is no direction or other recommendations from the European Union to implement such measures (in comparison with the zero or maximum $0.5 \mathrm{~g} / \mathrm{l}$ BAC levels), the widespread use of DI courses in the EU countries is even more significant. According to research conducted as part of the ANDREA project (Bartl et al., 2002), various evaluations of driver rehabilitation courses for drink drivers (who are not problem drinkers) indicate that the rate of reoffending can be reduced by $50 \%$ when compared to control groups without course participation. Thus, it can be shown that DI courses which are aimed at increasing the responsibility of a driver do indeed lead to safer driving behaviour and a better understanding of individual risks in traffic. The future legal basis for conducting special therapies for problem drinkers or frequent repeat offenders must be established by the governments on the EU level. Suitable methods and infrastructure have been developed in most of the countries, and are just waiting to be put into action.

Acknowledgements: The project was implemented as part of the Traffic Psychology International (TPI) initiative - www.traffic-psychology-international.eu. The data for selected countries was collected by TPI members.

\section{LITERATURE}

Alles Führerschein.at (2010). Hermes Project-final report. Retrieved May 27, 2015, from http://www.alles-fuehrerschein.at/ HERMES/documentation/HERMES\%20final\%20report.pdf.

Bartl, G. (2003). Analysis of driver rehabilitation programmes. GOCA - Your Safe Mobility Congress. Brussels.

Bartl, G., Assailly, J., Chatenet, F., Hatakka, M., Keskinen, E., \& Willmes-Lenz, G. (2002). EU-Project "Andrea". Analysis of Driver Rehabilitation Programmes. Wien: Kuratorium für Verkehrssicherheit.

Beirness, D., \& Simpson, H. (1997). Study of the Profile of HighRisk Drivers. Ottawa, Ontario, Canada: Transport Canada.

Boets, S., Meesmann, U., Klipp, S., Bukasa, B., Braun, E., \& Panosch, E. (2008). State of the art on driver rehabilitation: literature analysis \& provider survey. Deliverable d 5.1. 1, driving under the influence of drugs, alcohol and medicines (druid). Technical report, KfV.

Briem, V., \& Hedman, L. R. (1995). Behavioral effects of mobile telephone use during simulated driving. Ergonomics, 38(12), pp. 2536-2562.
Bukasa, B., Panosch, E., Klipp, S., Boets, S., Roesner, S., Kraus, L., Gaitanidou, L, \& Assailly, J., P. (2009). Validation of Existing Driver Rehabilitation Measures. Deliverable 5.2. 4, driving under the influence of drugs, alcohol and medicines (druid). Technical report, KfV.

Burns, P. C., \& Wilde, G. J. (1995). Risk taking in male taxi drivers: Relationships among personality, observational data and driver records. Personality and Individual Differences, 18(2), pp. 267-278.

Canadian Council of Motor Transport Administrators (2010). Canada's Road Safety Targets to 2010. Retrieved May 26, 2015 from http://www.tc.gc.ca/media/documents/roadsafety/crs target.pdf.

Christ, R., Delhomme, P., Kaba, A., Mäkinen, P., Sagberg, F., Schulze, H., et al. (1999). GADGET. Guarding Automobile Drivers through Guidance Education and Technology. Final Report. Wien: Kuratorium für Verkehrssicherheit.

Davies, G., Broughton, J., Harland, D., \& Turnbridge, R. (1999). Drink/driver rehabilitation courses in England and Wales. Crowthorne, UK: Transport Research Laboratory.

Elander, J., West, R., \& French, D. (1993). Behavioral correlates of individual differences in road-traffic crash risk: An examination of methods and findings. Psychological Bulletin, 113(2), p. 279.

European Commission. (2015). Road safety and alcohol. Retrieved March 19, 2015, from http://ec.europa.eu/transport/ road_safety/specialist/knowledge/alcohol/index_en.htm.

European Road Safety Observatory. (2007). Alcohol - diagram and summary. Retrieved on June 23, 2015 from: http://ec.europa.eu/transport/wcm/road_safety/erso/knowledge/Content/05_alcohol/alcohol.htm.

Evans, L. (1991). Traffic safety and the driver. New York: Van Nostrand Reinhold Co.

Goodwin, A., Kirley, B., Sandt, L., Hall, W., Thomas, L., O’Brien, N., \& Summerlin, D. (2013).

Countermeasures that work: A highway safety countermeasures guide for State Highway Safety Offices, 7th edition. (Report No. DOT HS 811 727). National Highway Traffic Safety Administration, Washington, DC. pp. 233-234.

Gomes, A. D. (1993). O tráfego como sistema e como cultura (The road traffic as a system and as a culture). In J. Santos, $\mathrm{Fa}$ tores Humanos no Tráfego Rodoviário (Human Factors in Road Traffic ) (pp. 21-33). Braga: Psychology Laboratory, University of Minho.

Hatakka, M., Keskinen, E., Baughan, C., Goldenbeld, C., Gregersen, N. P., Groot, H. S., et al. (2003). Basic driver training: New Models, EU-project, final report. Finland: Department of Psychology, University of Turku.

Jacobshagen, W. (1997). Nachschulungskurse für alkoholauffällige Fahranfänger (NAFA) - Kurspraxis, Wirksamkeit und Akzeptanz. Köln: TÜV Rheinland.

Jacobshagen, W. (1998). Nachschulungskurs für alkoholauffällige Fahranfänger nach dem Modell NAFA in Deutschland: Klientel, Kursdurchführung, Wirksamkeit und Akzeptanz. Bergisch-Gladbach: Bundesantstalt für Straßenwesen. 
Jonah, B. A. (1986). Accident risk and risk-taking behavior among young drivers. Accident Analysis \& Prevention, 18(4), pp. $255-271$.

Juhnke, G. A., Sullivan, T. J., \& Harman, A. E. (1995). Attitude changes in DWI offenders: a study of a short-term treatment program. Journal of Addictions \& Offender Counseling, 15(2), pp. 51-58.

Keskinen, E. (1996). Why do young drivers have more accidents? Berichte der Bundesanstalt für Strassenwesen: Mensch und Sicherheit Heft M, 52.

Kloeden, C., McLean, A., Moore, V., \& Ponte, G. (1997). Travelling Speed and the Risk of Crash Involvement. Australia: University of Adelaide.

Koornstra, M. J. (2009). Risk-adaptation theory. Transportation research part F: traffic psychology and behavior, 12, pp. 77-90.

Lajunen, T., \& Summala, H. (1997). Effects of driving experience, personality, driver's skill and safety orientation on speed regulation and accidents. In T. Rothengatter, Traffic and transport psychology. Theory and application (pp. 283-295). Bingley: Emerald Group Publishing.

Lewis-Evans, B. (2012). Testing models of driver behavior. Proefschrift. Groningen: University of Groningen.

Lim, C., \& Dewar, R. (1989). Driver cognitive ability and traffic accidents. Canada: Calgary.

Martinez, R. (1997). A Compilation of Motor Vehicle Crash Data from the Fatality Analysis Reporting System and the General Estimates System. Washington: National Highway Traffic Safety Administration.

Mayhew, D. R., \& Simpson, H. M. (2002). The safety value of driver education an training. Injury Prevention, 8(suppl 2), pp. ii3-ii8.

Michalke, H., Barglik-Chory, C., \& Brandstätter, C. (1987). Effizienzkontrolle von Gruppentrainingsmaßnahmen für alkoholauffällige Kraftfahrer - Driver Improvement. Wien: Kuratorium füe Verkehrssicherheit.

Michon, J. (1985). A critical view of drivers behavior models: What do we know, what should we do? In R. S. L. Evans, Human behavior and traffic safety (pp. 485-520). New York: Plenum Press.

Moller, H. J. (2009). Driver health and traffic safety: an overview. In J. Verster, S. R. Pandi-Perumal, J. G. Ramaekers, \& J. J. de Gier (Eds.), Drugs, Driving and Traffic Safety (pp. 1-22). Basel: Birkhäuser.

Nilsson, G. (2004). Traffic safety dimensions and the power model to describe the effect of speed on safety (Doctoral dissertation, Lund University).

NHTSA. (2004). Safe Routes to School: Practice and Promise. Author, Washington, DC. Available at www.nhtsa.dot.gov/ people/injury/pedbimot/bike/Safe-Routes-2004/. Accessed March 10th, 2016.

Parker, D., West, R., Stradling, S., \& Manstead, A. S. (1995). Behavioral characteristics and involvement in different types of traffic accident. Accident Analysis \& Prevention, 27(4), pp. 571-581.
Peräaho, M., Keskinnen, E., Laapotti, S., Katila, A., \& Hernetkoski, K. (2010). A proposal for driving instruction in three stages to acquire a B-driving license. 3rd Scientific NORBIT Conference and 5th Japanese-Nordic Conference (22nd-24th Aug). University of Turku.

Praxenthaler, H. \&. (1985). Verkehrsmedizin in Gegenwart und Zukunft [Traffic medicine at the present and in the future]. In H. Wagner, Verkehrsmedizin [Traffic medicine] (pp. 1-10). Berlin: Springer.

Ranney, T. A. (1994). Models of driving behavior: a review of their evolution. Accident Analysis \& Prevention, 26(6), pp. 733-750.

Risser, R. (1997). Validity of driver's diagnostics and selection. In R. Risser, Assessing the driver (pp. 89-101). Braunschweig: Rot-Gelb-Grün.

Roberts, I. G., \& Kwan, I. (2001). School-based driver education for the prevention of traffic crashes. The Cochrane Library.

Rumar, K. (1985). The role of perceptual and cognitive filters on observed behavior. In L. Evans \& R.C. Schwing (Eds.), Human Behavior and Traffic Safety (pp. 151-170). NY: Plenum Press.

Schützenhöfer, A., \& Krainz, D. (1999). Auswirkungen von Driver Improvement - Maßnahmen auf die Legalbewährung. Zeitschrift für Verkehrsrecht, 4 , pp. 138-143.

Silva, M. F. P. (2004). Learning and behavior in the car driving. Dissertation in Psychology, specialization in Educational Psychology. Faculty of Psychology and Educational Sciences of the University of Coimbra (unpublished thesis).

Silva, M. F. P., Jorge A. S., \& Meireles, A. (2014). Road Accident: Driver Behavior, Learning and Driving Task. Procedia Social and Behavioral Sciences, 162, pp. 300-309.

Sommer, M., Herle, M., Häusler, J., Risser, R., Schützhofer, B., \& Chaloupka, C. (2008). Cognitive and personality determinants of safe driving behavior. Transportation Research Part F, pp. 362-375.

Stanton, N. A., Walker, G. H., Young, M. S., Kazi, T., \& Salmon, P. M. (2007). Age and gender differences in risk-taking behavior as an explanation for high incidence of motor vehicle crashes as a driver in young males. Injury Control and Safety Promotion, 10(3), pp. 123-130.

TIRF. (1997). DWI Repeat Offenders - A Review and Synthesis of the Literature. Ontario: Health Canada.

Vernick, J. S., Li, G., Ogaitis, S., MacKenzie, E. J., Baker, S. P., \& Gielen, A. C. (1999). Effects of high school driver education on motor vehicle crashes, violations, and licensure. American Journal of Preventive Medicine, 16(1), pp. 40-46.

Vèzina, L. (2001). High Risk Drivers: A Literature Review. Québec, QC: Société de l'assurance automobile du Québec.

Walker, G. H., Young, M. S., Kazi, T., \& Salmon, P. M. (2007). Changing drivers' minds: the evaluation of an advanced driver coaching system. Ergonomics, 50(8), pp. 1209-1234.

Wilde, G. J. (1994). Target Risk. Dealing with danger of death, disease and damage in everyday decisions. Toronto: PDE Publications. 
Wilde, G. J. (1978). Theorie der Risikokompensation der Unfallverursachung und praktische Folgerungen für die Unfallverhütung. Heft der Unfallkunde 130, pp. 134-156.

World Health Organisation. (2015). Global status report on road safety 2015. Author, Geneva.

Available at http://www.who.int/violence_injury_prevention/en/. Accessed March 9th, 2016.

World Health Organisation. (2013). Global status report on road safety. WHO, Geneva.

Yagil, D. (1998). Gender and age-related differences in attitudes toward traffic laws and traffic violations. Transportation Research Part F, pp. 123-135. 